\title{
Abiotic and microbially influenced corrosion on buried iron artefacts
}

\author{
D. Lewicka ${ }^{1} \&$ A. Pfennig ${ }^{2}$ \\ ${ }^{1}$ TU Berlin Institute of Technology, Germany \\ ${ }^{2}$ HTW University of Applied Sciences Berlin, Germany
}

\begin{abstract}
Microbial influences on the corrosion process of archaeological iron artefacts are seldom mentioned in conservation literature. However, the theoretical discussion - based on knowledge from adjacent sciences - indicates that the phenomenon MIC (for microbially induced corrosion) is very likely to occur on archaeological objects during burial - and maybe even beyond this period. In generalized scenarios, where microbial life coincides with "object life", distinctive issues on the condition of findings, relevant for means of conservation, were pointed out. An experiment to distinguish effects of MIC from effects of abiotic corrosion is suggested as an approach to specific research on MIC under the means of conservation.
\end{abstract}

Keywords: microbially influenced corrosion, MIC, corrosion of buried iron.

\section{Introduction}

Conservators of archaeological heritage are used to deal with both, corrosion of iron artefacts and microbial influence on the decay of artefacts - though the coherence of those two phenomena may probably be hard to see at first.

Microbial cells are omnipresent in our environment and when those happen to come across suitable living conditions supplying sources of energy, nutrients and water they may settle and breed to colonies of yet visible size. Those attached, so called sessile cells excrete extracellular polymeric substances (EPS) forming a gelatinous matrix - the biofilm. Those biofilms are responsible for the solution and evolution of conservation problems: when either degrading artefacts while burial without a trace or degrading artefacts partly, leaving the remaining material in a fragile condition requiring conservation treatment. However, the 
decomposition of objects made from organic materials can easily be associated with all those phenomena we know from our daily lives, as mouldy food, unpleasant odours and disfigured surfaces. But is it imaginable that there may be a connection between those and the electrochemical corrosion process of metal artefacts?

Matching data derived from literature indicate that approximately $20 \%$ of all corrosion phenomena on metals are subject to microbial influence [1, p. 90; 2]. This microbially influenced corrosion (MIC) appoints to the manipulation of the electrochemical corrosion process by microorganisms in the broadest sense. It summarizes various phenomena which are mostly associated with the metabolism and/or biofilms formed by a multitude of different microorganisms. In the industrial sector MIC causes damage resulting in heavy financial losses due to interferences in functionality of materials and facilities.

Knowing this however, it may be of interest for the section of archaeological heritage to be aware if MIC might have an impact on buried artefacts as well before and after excavation. Is the model of MIC applicable on heritage? Are there relevant differences in the effects of microbially influenced and abiotic corrosion when it comes to conservation? If so, how could these affect specific immaterial values and issues relevant for handling and scientific research? And above all, how can these questions be answered when knowledge on MIC is poor in the section of conservation science?

\section{Background, research questions and proceeding}

This work emerged from the simple question that comes along when a person studying conservation starts to interest for soil science: "When there are microorganisms in soil using iron as a source of energy what would happen with buried iron artefacts on their way?”

Due to the professional approach to objects (as material on the one hand and carriers of information on the other hand) a catalogue of questions and properties relevant for interpretation, practice and research where pointed out to specify the goals for research on MIC from the perspective of conservation:

I. Aspects of aesthetics and cultural sciences

a) level of information of the "original surface";

b) impact of the superficial corrosion products on the surface aesthetics (colour, texture and shape);

c) influence on mineralization;

d) stimulation of MIC by certain using and wear and tear;

II. Aspects of chemical stability and conservation

a) remaining corrosion potential;

b) passivation or local corrosion;

c) structure and morphology of corrosion layer(s);

d) $\mathrm{pH}$ of electrolyte on surface;

e) remnants of biofilm on surface; 
III. Aspects of physical stability

a) mechanical stability and stress resistance (during excavation, transport and treatment);

IV. Understanding and prognosing the process

a) changes of reaction due to changing environments while excavation;

b) risk assessment for iron objects with biofilms/ MIC.

Since issues on MIC have scarcely been even mentioned in conservation literature the topic was approached by consulting results from adjacent sciences as microbiology, soil science and research on corrosion mainly from the industrial sector. These where merged with the focus of sciences in touch with archaeological objects as archaeology, archaeometry and conservation of course to shape an appropriate framework for a theoretical approach to this very specific subject.

On the one hand such objects normally pass through a burial period of hundreds or thousands of years. On the other hand the processes that take place in soil affecting material decay are very complex, so it is hard to figure out the exact causes for certain effects. This is why the investigation on MIC on archaeological objects needs very careful proceeding when aiming on reliable scientific theories.

Main research issue was therefore: "Which microbial influences on corrosion of archaeological iron artefacts under burial conditions are probable and how can these be examined realistically and evaluable in laboratory experiments with recent material?”

This work is arranged in three parts: the first one collects aspects of different sciences relevant for the subject. The second part discusses possible scenarios for MIC on archaeological objects. The third part suggests such an experiment for the investigation of those specific issues listed above in groups I-IV.

The experiments suggested where not performed practically, for an interdisciplinary project is needed to gather the very specialized knowledge from the sciences mentioned. This work is a basis for further research pointing out the distinctiveness and the specialized focus needed in this field.

\section{Merging knowledge from various sciences into a consistent setting}

The following parts sketch the main aspects for a schematic understanding of the interactions between microorganisms and iron. Therefore situations having in common the parameters burial, iron and microorganism are summed to evaluate if MIC might occur on buried archaeological iron as well.

\subsection{Biochemical weathering}

European soils are inhabited by approximately $1,101,001 \times 10^{14}$ to $1,101,001 \mathrm{x}$ $10^{16}$ microbial individuals per $1 \mathrm{~m}^{2}$ [3]. Soil science examines the decomposition 
of non-organic soil components by those microorganisms as biochemical weathering. Here material is broken down by exudates excreted by the microbial cells thereby changing it chemically into a suitable nutrient condition. These free components are finally absorbed into the cell.

Every microbial cell needs iron as a trace element - just like human beings for the maintenance of physical health. But besides there is a group of bacteria, called chemolithotroph, using iron as a source of energy [4].

In both cases a relation between the element iron and the microbial metabolism becomes clear. More detailed description of the process and a scenario how it could be of importance follow below.

\subsection{Outlines of MIC}

In Germany there is a clear definition for corrosion determined by DIN 50900, part 3 as "reaction of a material with its environment, which leads on a measurable changing of properties which can result in corrosion damage, which is an interference of the material and/or its environment" [5, p. 2]. Referring to this there are three definitions for MIC quoted in the following:

Linhard [6, p. 69-79] points out that "MIC is no distinct mechanism; it is rather a significant, direct or indirect influence of the electrochemical system metal/medium by the organisms".

Eul [5, p. 1ff] states that “'biocorrosion' is the synergism of two elementary processes of the living and the inanimate nature, biofilm formation and corrosion, which have a negative effect on techniques and economy" and "[...] the material and its environment, the (corrosion) medium [...] are regarded together: they form the corrosion system".

Suter [7] explains the phenomenon as follows: "Processes of biocorrosion [...] on metal surfaces are closely connected with microorganisms or the products of their chemical activity. Corrosive reactions are mainly influenced when microorganisms produce a surface-covering biofilm. Several investigations revealed, that MIC is caused and influenced most by a multitude of different species".

Eul [5, p. 18] names biofilms as a significant factor for MIC but Little et al. [8m pp. 1006-1017] cite studies indicating that even single sessile microbial cells can be associated with corrosion phenomena on metal surfaces.

Experience shows "the interaction of biofilm and material causing microbial material damage $[\ldots]$ to be a very complex composition of physical, chemical and biological processes. The mechanisms in particular can rarely be separated exactly - at least not because of the multitude of involved microorganisms" [5, p. 18].

What becomes clear is that MIC is not a different mechanism to abiotic electrochemical corrosion. It is more an influence or conjunction between microbial life and the thermodynamical process. 


\subsection{Mechanisms of MIC}

Though the variety of influences makes it difficult to explain and diagnose MIC, several distinctive mechanisms could be determined by experts so far:

The physical presence of microbial cells can deplete the access of oxygen to the metal surface. As a consequence of the oxygen gradient, differential aeration corrosion cells may arise [6, p. 71].

Depending on the particular metabolism, all or just a few species produce corrosive compounds having an impact on the electrochemical process: acids, chelating agents and gases [5, p. 18ff; 6, p. 74; 9, pp. 4-13]. Some microorganisms can excrete sulphurous, sulphuric and nitric acid but all microorganisms excrete carbon dioxide, which can partly react to carbonic acid in aqueous solution [5, p. 16; 9, p. 8]. Likewise all microorganisms excrete organic acids as a metabolic intermediate [5, p. 19]. Acids can be accumulated in biofilms up to local concentrations of $<1 \mathrm{pH}$, which can cause acid corrosion [5, p. 19; 9, p. 9]. Moreover, organic acids can react as chelating agents where, removed after ten months of burial, they were covered with pitting in intervals of 20 to $50 \mathrm{~cm}$. In some parts the material has been dissolved up to a complete penetration of the pipe. Some parts undergo passivation and are free from damage. As an explanation for the occurrence of the unexpected corrosion attack the investigators detected the following scenario: the original soil was naturally inhabited by SRB expanding to the metal surface and using the present metal as a sink for hydrogen sulphide which is a toxic end product of their metabolism. Instead of the accumulation in the biofilm, this noxious compound reacted with dissolved iron ions to ferrous sulphide [10], associating with metal cations by cracking stable compounds - stimulating the anodic reaction [5, p. 20; 9, p. 12].

Electrochemical models for corrosion associated with dissimilatory sulphate reduction caused by sulphate reducing bacteria (SRB) are discussed from 1934 to this day [5, p. 23ff; 6, p. 69]. Eul [5, p. 22] suggests that under anaerobic conditions those organisms use alternative electron acceptors for oxygen, such as sulphate forming hydrogen sulphide as a characteristic end product. An example will follow below.

In most cases several mechanisms occur at the same time causing corrosion [5, p. 18].

\subsection{MIC under burial conditions}

Most archaeological objects have in common the burial - but there are fields in modern industries which can be compared to archaeological burial. Among these are wastewater pipes and gas pipelines on which MIC causes damage in the range of billions of dollars per year [1, p. 89].

A detailed documentation of MIC by Allertshammer et al. [9] can be used as a comparable setting: The issue is about newly installed pipes under a building which had to be examined because of interferences in performance. When the pipes were removed after ten months of burial they were covered with pitting in intervals of 20 to $50 \mathrm{~cm}$. In some parts the material has been dissolved up to a 
complete penetration of the pipe. Some parts undergo passivation and are free from damage. As an explanation for the occurrence of the unexpected corrosion attack the investigators detected the following scenario: the original soil was naturally inhabited by SRB expanding to the metal surface and using the present metal as a sink for hydrogen sulphide which is a toxic end product of their metabolism. Instead of the accumulation in the biofilm, this noxious compound reacted with dissolved iron ions to ferrous sulphide.

\section{Conclusion for MIC on buried archaeological objects}

This knowledge on MIC justifies the assumption that MIC might occur on archaeological artefacts as well. Regarding the enormous number of microbial individuals inhabiting the terrestric realm, it appears unlikely that during burial periods of hundreds or thousands of years iron object surfaces may not appear as attractive habitats to microorganisms. Assuming that microorganisms would have a greater "interest" in maintaining their life functions than preserving human heritage it can be suggested to transfer the concept of MIC on archaeological artefacts. Indeed damage on cultural heritage needs to be evaluated differently from the kinds of damages corrosion causes in the industry - but the basic mechanisms on the material are driven by the same physical, chemical and biological processes.

\section{Scenarios for MIC on buried artefacts as working hypothesis}

In most cases archaeological objects had a "former life" close to human activity. Mainly this is a significant factor for the value of the object - but could this period before burial have an influence on the susceptibility for MIC as well? Apart from the view that microbial cells are omnipresent on every surface, items used in areas of life with high presence of microbial cells, or such dealing with "biomass" in the broadest sense, might have been inhabited extensively before burial. These could be agricultural tools, means of transportation on the ground, devices for food supply, items in close contact with the human or animal body and others. When the usage environment provided tolerable or attractive living conditions, biofilms could have grown on the surface in that period of time already - maybe paving the way for MIC.

When entering the microbial habitat soil, an enormous number of microorganisms attain access to the surface of the object. Though several factors seem to be important for the course of population and subsequently MIC:

- presence and composition of the microbial population in situ;

- depth in which the object is inserted;

- presence of other objects and materials which may be metabolized;

- site and its soil properties;

- season and climate;

- conditioning film on surface (irreversibly adherent layer of macromolecules); 
- microbial growth on surface before burial.

Therefore it can be assumed that microbial growth and its influence on the corrosion proceeds heterogeneously on archaeological artefacts.

Although a purposeful destructive microbial attack is very unlikely, microbial populations may probably benefit from preferential growth on buried metal objects in ecosystems - as the example above showed. Besides metal as a sink for noxious compounds, iron as an essential element may be attractive as well: when the supply for iron from soil solution is poor, microorganisms are able to excrete so called siderophores, which are substances with a high affinity for iron ions changing them chemically. It could be possible that by changing iron(III)ions into iron(II)ions stable corrosion layers could be broken down by siderophore action. On the one hand this could increase formerly decelerated corrosion rates. On the other hand it could lead to a loss of information trapped in corrosion layers, like inclusions of organics and mineralized structures which have a high value for archaeological and archaeometric research.

However, it could be also possible that a metal surface could be affected when metabolic products of decomposing adjacent substrates would migrate to the surface. For example, when carbonic acid is produced as a consequence of metabolizing biomass, subsequently acid corrosion is caused. This could happen very distinctively when the decaying material and the metal surface are connected by a mutual biofilm. This may happen in cases of composite objects, randomly spread biomass from the ecosystem but also in cases of human burials, when objects are placed in close contact with the body.

Another specific aspect when regarding MIC on archaeological iron is the structure of the material: a characteristic of ancient wrought iron are strung-out slag inclusions. The area between those and the grain boundaries is highly susceptible to cracking. The resulting interstices often fill with corrosive solution, provably causing weak spots for corrosion attack. Little et al. [8, p. 1010f] detected cracks as preferential habitats for microorganisms. It could be possible that microorganisms inhabit these spots so that their metabolic end products accumulate and cause local damage.

Finally it has to be taken into account that biofilms create a protecting environment for microorganisms maintaining tolerable living conditions when environmental parameters change. This could mean that although a dramatic change in the outer situation occurs during and after excavation of an artefact, the microbial population might survive partly on the object surface. Especially when objects are wrapped in plastic, the inside micro climate may maintain suitable living conditions - maybe enabling (further) MIC.

\section{Conclusions for the specific research on MIC in the field of conservation}

The scenarios highlight that results from other sciences provide a basic approach in understanding, but they also clearly point out that those specific questions listed in part 2 require specialized research under the light of conservation science. The distinctive focus on archaeological heritage is an important factor 
for the evaluation of the damage caused by MIC - which differs from the evaluation of damage required in research on corroded facilities. The damage caused to aesthetics and the level of information, high in valuables in heritage, cannot be deduced from the given information. The risk assessment for further corrosion potential induced by biofilms after excavation cannot be evaluated theoretically. The understanding of the process and the differences between abiotic and microbially influenced corrosion might possibly bring improvement of common conservation techniques and more precise concepts for non-invasive preventive conservation in future.

\section{Notes on the experiment}

The following notes for an experiment draw a rough overview for a strategy aiming on the gain of empirical specialized insights on MIC. The basic idea is to induce corrosion on recent specimen under conditions where microbial influence is possible and sequences where microbial influence can be excluded. The specimens are charged with information resembling the idea of values highly regarded on artefacts, so the effect of value loss can be investigated. Referring to the conflict between the clear deduction of causes and the comparability to archaeological objects and influences on archaeological sites, naturally occurring soil with its inhabiting microbial population is used for experiments in the laboratory - on the one hand left as extracted, on the other hand sterilized to expel microbial activity. Since microbiologists state that experiments in laboratory barely yield outcomes comparable to processes in natural habitats, an array in situ is included to monitor the effects and to check the laboratory outcomings for reliability. The experiments in laboratory allow control of the living conditions of the microorganisms. On the one hand this helps deducing causes for certain reactions. On the other hand it maybe could provide a kind of accelerated aging which might be helpful to encounter the contradiction of applying experiments with recent materials on archaeological material. The materials for the specimen should be carefully chosen to approach the properties of ancient wrought iron. The conflict here is that ancient metals have a heterogeneous structure due to working techniques; the experiments require a homogenous structure however to make sure the occurring corrosion phenomena on the specimen are comparable. For this reason a method for combining a heterogeneous structure with properties of ancient work pieces, which could be the mentioned slag inclusions for example, has to be developed.

Not least the immaterial values which are - though hard to record - a main aspect of the research goal require standards for a systematic score.

\section{Résumé and outlook}

In sum literature research showed that there is a lack of information on the microbial influence on corrosion of archaeological objects. The discussion of knowledge derived from microbiology, soil and corrosion sciences lead to the assumption that MIC mechanisms might occur in this field as well. Therefore it 
is suggested to adopt the term microbially influenced corrosion for buried archaeological iron artefacts. The scenarios justify the assumption that damage on material, but as well on aesthetics, the level of information and other immaterial values could be possible - maybe even after excavation. However, deriving theoretically it is not possible to determine how these damages by microorganisms materialize on the object, and if there is a difference between effects of microbially influenced corrosion and abiotic corrosion.

It is up to the experts of our profession to figure out and decide if it is relevant for us to let the concept of MIC have an effect upon our way of understanding the objects we are working with and the strategies we are applying to preserve them.

One of the main open questions is: "Is the expected benefit from research worth the effort needed?" Trying to answer this question theoretically ends up in an endless conceptual loop with the cost-benefit-analysis on the one side and the argument that only empirical data can pave the way for the solution on the other side. The conclusion is that specialized, empirical, interdisciplinary research will be necessary to assess, if the distinction between MIC and abiotic corrosion is relevant to conservation issues.

\section{References}

[1] Alsopp, D., Seal, K., Gaylarde, C., Introduction to Biodeterioration, Cambridge University Press: Cambridge New York Melbourne Madrid Cape Town, 2004.

[2] Flemming, H.-C., Biofilme - Entwicklung, Bedeutung, Auswirkungen, Mikrobiell beeinflusste Korrosion oft unerkannt weil unbekannt?, GfKORR - Gesellschaft für Korrosionsschutz e.V, DECHEMA e.V.: Frankfurt am Main, pp. 14-25, 2005.

[3] Scheffer, F., Schachtschabel, P., Lehrbuch der Bodenkunde, Enke Verlag:Stuttgart, pp. 82, 1989.

[4] Madigan, M. T., Martinko, J. M., Brock Mikrobiologie, Pearson Studium: München, pp. 33, 2009.

[5] Eul, U., Entwicklung und Einsatz einer Simulationsapparatur zum Nachweisund zur Verhinderung von mikrobiologisch beeinflußter Korrosion (MIC), Herbert Utz Verlag: Frankfurt, 1997.

[6] Linhardt, P., MIC an Metallen - eine Übersicht, Mikrobiell beeinflusst Korrosion oft unerkannt weil unbekannt?, GfKORR - Gesellschaft für Korrosionsschutz e. V, DECHEMA e.V.: Frankfurt am Main, 2005.

[7] Suter, T., Mikroelektrochemische MIC-Untersuchungen an verschiedenen Metallen, Mikrobiell beeinflusst Korrosion oft unerkannt weil unbekannt?, GfKORR - Gesellschaft für Korrosionsschutz e.V, DECHEMA e.V.: Frankfurt am Main, pp. 80-88, 2005.

[8] Little, B. J., Lee, J. S., Ray, R. I., Diagnosing Microbially Influenced Corrosion: A State-of-the-Art Review, Corrosion Vol. 62, No.11, 2006.

[9] Allertshammer, W., Warscheid, T., Schadensanalyse MIC - am Beispiel des Angriffes sulfatreduzierender Bakterien auf nichtrostenden Stahl 
388 Structural Studies, Repairs and Maintenance of Heritage Architecture XIII

imErdboden, Mikrobiell beeinflusst Korrosion oft unerkannt weil unbekannt?, GfKORR - Gesellschaft für Korrosionsschutz e.V, DECHEMA e.V.: Frankfurt am Main, pp. 119-129, 2005.

[10] Little, B. J., Lee, J. S., Ray, R. I., Diagnosing Microbially Influenced Corrosion: A State-of-the-Art Review, Corrosion Vol. 62, No. 11, 2006. 